\title{
Application of New Energy-saving and Environment-friendly Building Materials in Engineering
}

\author{
Xuejun Zhao \\ Building Materials Institute, Kunming Metallurgy College, Kunming 650033, China
}

Keywords: energy saving, environmental protection, building materials, engineering applications, waste of resources

\begin{abstract}
In recent years, green energy conservation, environmental protection and other issues have become a topic of great concern to people. The reason is that in recent years, the global ecological environment has been deteriorating and the resource crisis has been intensifying. Compared with western developed countries and regions, China still has a large gap. The aggravation and deterioration of the environment are very unfavorable to the construction of society. Aware of this, people begin to pay attention to the issue of energy conservation and environmental protection, and begin to strengthen the application of energy-saving and environment-friendly building materials in project construction, which will not only greatly help people's physical and mental health, but also facilitate the development of enterprises in a more smooth and orderly way. The author conducts an analysis and discussion on this point.
\end{abstract}

\section{Introduction}

The new energy-saving and environment-friendly materials are used in the process of production and manufacture, with brand-new technical means, to integrate the requirements of protecting the environment, reuse, energy conservation and soil conservation into the building materials, and apply them to the construction projects, so as to achieve the goal of energy conservation and consumption reduction. The new energy-saving and environment-friendly materials cover a wide range and have penetrated into every link of the construction project. On the one hand, the quality of the construction project can be improved; on the other hand, it is of great significance to improve the current ecological environment.

New economic and social situation, green environmental protection and energy saving become the main issues in people's lives, the use of these materials in the engineering construction, the environmental pollution caused by the relatively common building materials, and energy conservation and environmental protection material many is to waste realized using again, to a great extent, reduce the waste of resources. In the construction of building engineering, the use of these materials will reduce the harm to people's health to a certain extent. Therefore, it is worthy of extensive promotion and application.

\section{The Significance of Using Energy-saving Green Building Materials in Engineering}

With the development of national economy in recent years, the construction industry has also made great progress in this situation, especially the continuous improvement of construction technology, and the use standard of materials in construction is also increasing. Therefore, various kinds of energy-saving and environment-friendly materials have emerged in the society, and the appearance and application of these materials have played a very important role in promoting the development of engineering energy-saving. The application of energy-saving, green and environment-friendly building materials in the construction of engineering projects is a good improvement for the continuous use function of buildings. Besides, the satisfaction and comfort of buildings will be improved, and the overall environmental quality will be greatly improved. At the 
same time, the application of energy-saving and environment-friendly building materials in the process of engineering construction can also realize the concept of recycling waste into treasure. It is very energy saving to recycle various industrial wastes and solid wastes in various industrial construction. A lot of dust will be produced in the construction process, which will cause a certain degree of pollution to the atmosphere. Besides, there are also a lot of materials and quantities used in the construction, so the consumption of energy resources is also very large. So it's not as pollution

One of the serious industries, to achieve the goal of green environmental protection and energy conservation, strengthening the application of such building materials has a very significant promotion effect. In addition, with the continuous improvement of social economy and information technology, it is more necessary to carry out a very reasonable and effective way to achieve the goal of building energy conservation in cities and strengthen the application of green energy conservation and environmental protection materials.

From the current construction materials used in China, concrete hollow bricks are more commonly used in walls, and concrete hollow bricks are formed by mixing of powder coal, cement and sand and stone. In the concrete project construction process, need to combine the different demand of project, try to choose the specification of brick. Moreover, the layout of concrete hollow bricks is also diversified, so as to effectively use the holes in the bricks to improve the insulation performance of the building walls, and the heat flow route of hollow bricks will be lengthened accordingly.

\section{Application of New Energy-saving and Environment-friendly Materials in Engineering}

The application of energy-saving me tope material should take fully into account the function of building, and the obvious concave and convex parts should not appear on the model. The materials used should meet the requirements of indoor fire protection grade, and the materials with good insulation performance should be selected as far as possible to reduce indoor heat loss. If a lightweight partition wall is used, the heat conduction area should be strictly controlled, such as the partition wall of the office and warehouse, so as to avoid heat conduction to the room without temperature control. The new thermal insulation material can reduce the heat loss rate in the building. For example, add insulation material to light partition or add insulation material to light steel keel gypsum board. In architectural design, rooms that need to keep the walls warm must be insulated. The use of energy-saving wall materials can reduce the natural heat loss rate, thus saving energy for heating.

In the process of building engineering construction, various new building materials are needed to keep the exterior walls and roofs of buildings in all directions insulated. Most common buildings use hollow concrete blocks and reinforced concrete and other wall materials. As this kind of building materials is relatively simple in use, the requirements for building thermal insulation, thermal insulation and other requirements cannot be effectively met, so the building energy conservation and environmental protection standards cannot be met. In order to make the living house more comfortable and thermal insulation, it is necessary to choose new materials of green energy conservation and environmental protection. The insulation materials in the building wall are located in different positions, which can be divided into internal insulation, middle insulation and external insulation. The thermal insulation of the exterior wall of the building is mainly the insulation material on the outside of the bearing wall, which can significantly improve the thermal stability of the building. So in the home life, the time that USES air conditioning system and frequency also can reduce greatly. At present, in China's construction market, the use of external wall insulation materials are relatively large, such as foam mortar and polystyrene board. In addition, in the construction and construction process of the house building, the process required to deal with the external wall insulation is relatively complex, generally five or six. Some buildings also use rock wool board and fly ash hollow block as the insulation wall of the exterior wall, so as to reduce the heat transfer coefficient. The application of exterior wall insulation and energy saving technology in buildings can ensure the comfortable living environment and significantly reduce noise pollution. In addition, the seepage water and cracks caused by the structural temperature difference can also 
effectively improve the service life of the building structure, which is also the most useful for the indoor space to expand the phase transformation.

In China, due to the rapid development of the co-story building, the total amount of construction waste generated in the project is amazing. If not used, it will inevitably seriously pollute the environment. In addition, the current building model is not in line with the trend of social development and violates the strategic mode of sustainable law development. Therefore, in the future development, it is necessary to pay attention to the utilization of renewable resources, which can be used as the raw material of construction engineering, so as to reduce the generation of solid waste and reduce the impact of construction engineering on the environment. For example, in construction engineering, waste concrete can be used as the raw material, which can be treated and shaped scientifically and then made into recycled concrete and applied in construction engineering. In addition, when producing building materials, we should pay attention to their quality standards, so that they can reduce the content of harmful substances such as formaldehyde while meeting the needs of construction projects, so as to protect the personal safety of construction workers and owners and promote the development of the construction industry.

At present, in large public buildings, large area glass curtain wall is the main external maintenance structure, which has an important influence on building energy saving. Large area glass curtain wall should adopt the proportion material with good light transmission and strong heat insulation, and make full use of solar energy technology, install new energy glass material, install solar photo electricity board on the roof, replace the use of traditional energy, achieve the purpose of saving energy. For example, in a certain project, the solar photovoltaic panel, with an urgent area of $6700 \mathrm{~m}^{2}$, accounts for about $50 \%$ of the total lighting area of the building roof, and the power generation can reach 320k W. By adopting glass roof in a large area, the lighting rate of the building as a whole is significantly increased, and the electricity consumption of the building is also significantly reduced. Solar photovoltaic panels can be used in large areas, and they can also power other electrical equipment in the building, saving energy consumption in the building. In addition, building energy saving maintenance materials are also gradually to light quality, thermal insulation direction.

\section{Summary}

In conclusion, the new energy-saving and environment-friendly materials have their own advantages and should be able to implement the policy of scientific development in the construction project. On this basis, the quality of construction projects can be effectively improved which reduces the generation of construction waste and improves the utilization rate of resources. Therefore, in order to effectively improve the ecological environment, in the future development, increase the utilization of renewable resources, pay attention to the development of new energy-saving and environment-friendly building materials.

At present, people's requirements on environmental quality are constantly improved and environmental protection awareness is gradually strengthened. Therefore, construction projects need to meet the requirements of the owner's living environment while ensuring the quality of buildings, and develop new energy-saving and environment-friendly building materials vigorously. First of all, scholars in the construction industry should strengthen their research on new energy-saving materials. On the basis of existing energy-saving materials and on the basis of science and technology, researchers should develop new and high-quality building materials to promote the development of the construction industry. In addition, the management department of construction engineering should pay attention to the quality supervision of construction materials, actively introduce new construction materials and construction technology, attach importance to the cooperation between various departments, and apply high-quality materials to construction projects. In the process of building construction, the quality of construction should be paid attention to, so as to ensure that building materials can give full play to their own value and implement sustainable development policies. In construction, it is necessary to select appropriate building materials according to the characteristics of different buildings and regions, attach importance to the specific application of 
insulation materials and composite materials, promote the development of packaged and serialized products, and promote the development of the construction industry in an all-round way. In this way, new energy-saving and environment-friendly materials can be effectively applied to specific construction projects, which can not only ensure the quality of construction projects, but also meet the specific needs of owners, implement sustainable development strategies, and lay a foundation for building a harmonious socialist society.

In the process of engineering construction and construction, glass is a kind of material that USES quite a lot. At present, various kinds of glass appear in the construction market. In the construction and construction, in order to minimize the construction cost, some relatively cheap glass will be selected, and the environmental protection performance of these glass cannot be guaranteed at all, which will also cause a great adverse impact on the building environment. Some of the selected glass, such as photochemical glass, vacuum glass, foam glass, low-radiation glass and hollow glass, have better environmental protection and energy conservation performance and have different benefits.

\section{References}

[1] Yao wenlong. Analysis on the application of new energy-saving and environment-friendly materials in building engineering [J]. Building materials and decoration, 2017(37):5253. (In Chinese)

[2] Yang haijiang. Application of new energy-saving and environment-friendly materials in building engineering [J]. Shanxi architecture, 2015(23):160-161. (In Chinese)

[3] Xu haifeng. Application status and trend analysis of new energy-saving building materials [J]. Commodities and quality, 2015(16):277. (In Chinese)

[4] Zhang sen. On the application value and approach of energy-saving and environment-friendly materials in residential buildings [J]. Intelligence,2016(09):327-329. (In Chinese)

[5] zhao xuwen. Energy-saving and environment-friendly materials and green packaging add luster to China's low-carbon economy [J]. Shanghai packaging, 2015(26): 87-88. (In Chinese).

[6] Information on http://www.weld.labs.gov.cn Gao nan. Discussion on several new environment-friendly energy-saving building materials [J]. Science and technology information, 2014(28): 131-133. (In Chinese). 